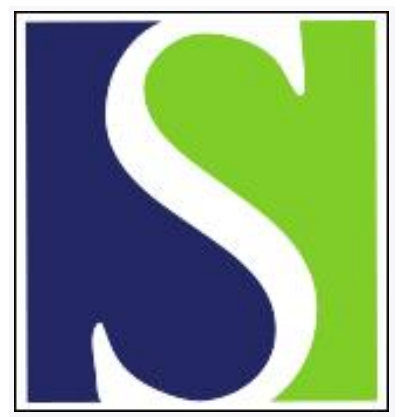

Scand J Work Environ Health 2017;43(5):415-425

https://doi.org/10.5271/sjweh.3663

Published online: 07 Aug 2017, Issue date: 01 Sep 2017

Cumulative occupational mechanical exposures during working life and risk of sickness absence and disability pension: prospective cohort study

by Sundstrup E, Hansen ÅM, Mortensen EL, Poulsen OM, Clausen T, Rugulies R, Møller A, Andersen LL

Using a biomechanical job exposure matrix combined with Danish registers, cumulative occupational mechanical exposures throughout life (ie, more years with heavy and frequent lifting, and kneeling work) predicted risk of long-term sickness absence among older workers. Importantly, heavy lifting throughout working life was associated with disability pension.

Affiliation: National Research Centre for the Working Environment, Lersø Parkallé 105, 2100 Copenhagen, Denmark. E-mail: esu@nrcwe.dk

Refers to the following texts of the Journal: 1992;18(2):105-112

2012;38(6):516-526 2013;39(6):599-608 2016;42(6):481-489

$1993 ; 19(3): 208-214$

The following articles refer to this text: 2019;45(6):610-621;

2020;46(4):373-381; 0;0 Special issue:0

Key terms: cohort study; disability pension; exposure; JEM; job exposure matrix; kneeling; lifting; long-term sickness absence; lower body JEM; occupational mechanical exposure; physical demand; prospective cohort study; sickness absence; standing; vibration; working life

This article in PubMed: www.ncbi.nlm.nih.gov/pubmed/28783203

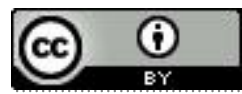




\title{
Cumulative occupational mechanical exposures during working life and risk of sickness absence and disability pension: prospective cohort study
}

\author{
By Emil Sundstrup, PhD, ${ }^{1}$ Åse Marie Hansen, PhD, ${ }^{1,2}$ Erik Lykke Mortensen, PhD, ${ }^{2,3}$ Otto Melchior \\ Poulsen, DrVetSc, ${ }^{1}$ Thomas Clausen, PhD, ${ }^{1}$ Reiner Rugulies, PhD, ${ }^{1,2,4}$ Anne Møller PhD, ${ }^{5,6}$ \\ Lars L Andersen PhD ${ }^{1,7}$
}

\begin{abstract}
Sundstrup E, Hansen ÅM, Mortensen EL, Poulsen OM, Clausen T, Rugulies R, Møller A, Andersen LL. Cumulative occupational mechanical exposures during working life and risk of sickness absence and disability pension: prospective cohort study. Scand J Work Environ Health. 2017;43(5):415-425. doi:10.5271/sjweh.3663
\end{abstract}

\begin{abstract}
Objectives The aim of this study was to determine the prospective association of cumulative mechanical exposure during working life with health-related labor market outcomes.

Methods This prospective cohort study combines data from 5076 older workers (age 49-63 years) from the Copenhagen Aging and Midlife Biobank with a job exposure matrix and a national register containing information on social transfer payment. By coding individual job histories from the Danish version of ISCO-codes (International Standard Classification of Occupations), we calculated cumulative occupational mechanical exposures from a JEM for ton-years (lifting $1000 \mathrm{~kg}$ each day in one year), lifting-years (lifting loads weighing $\geq 20 \mathrm{~kg}>10$ times each day in one year), kneeling-years (kneeling for one hour each day in one year) and vibration-years (whole-body vibration for one hour each day in one year). Cox-regression analyses estimated the relative risk of register-based long-term sickness absence (LTSA) and disability pension with cumulative occupational mechanical exposures throughout working life. Analyses were censored for competing events and adjusted for multiple confounders.
\end{abstract}

Results During the follow-up period, 970 persons (19.3\%) had $\geq 1$ episode of LTSA and 85 persons $(1.7 \%)$ were granted a disability pension. Number of ton-, lifting- and kneeling-years showed an exposure-response association with increased risk of LTSA $(\mathrm{P}<0.0001)$. In addition, both long term $[\geq 20$ years; hazard ratio (HR) $1.7695 \%$ CI 1.39-2.22] and short term (<10 years; HR $1.2095 \%$ CI 1.02-1.41) exposure to kneeling work increased the risk of LTSA. Lifting-years, but not the other mechanical exposures, were associated with risk of disability pension (HR 1.75 95\% CI 1.01-3.04).

Conclusions Cumulative occupational mechanical exposures during working life - such as lifting and kneeling work - increased the risk of LTSA. Importantly, being exposed to lifting increased the risk of disability pension.

Key terms job exposure matrix; JEM; kneeling; lifting; long-term sickness absence; lower body JEM; physical demand; standing; vibration.

Long-term sickness absence (LTSA) and disability pension constitute major public health issues in many western societies and partly reflects the interplay between health and working conditions. A proportion of individuals on LTSA never return to work, and may later obtain a disability pension (1-3). Being excluded from the labor market due to disability pension may cause financial problems, social isolation, and health deterioration (4).
Furthermore, the socioeconomic burden is substantial in terms of benefit claims, production loss, and extensive use of healthcare services (5). To secure a long, healthy and productive working life, knowledge on risk factors for LTSA and disability pension is therefore needed.

An occupational career consisting of numerous physically demanding work tasks may lead to health problems and challenge work participation in older age. Several pro-

1 National Research Centre for the Working Environment, Copenhagen, Denmark.

2 Department of Public Health, University of Copenhagen, Denmark.

3 Center for Healthy Aging, University of Copenhagen, Denmark.

4 Department of Psychology, University of Copenhagen, Denmark.

5 Department of Occupational Medicine, Holbæk Hospital, Denmark.

6 The Research Unit for General Practice and Section of General Practice, Department of Public Health, University of Copenhagen, Denmark.

7 Department of Health Science and Technology, Physical Activity and Human Performance group, SMI, Aalborg University, Denmark.

Correspondence to: Emil Sundstrup, National Research Centre for the Working Environment, Lersø Parkallé 105, 2100 Copenhagen, Denmark. [E-mail: esu@nrcwe.dk] 
spective cohort studies have linked exposure to mechanical work factors such as heavy lifting, kneeling, and whole body vibration with increased risk of LTSA (6-9). However, these studies have mainly focused on occupational exposures in participants' most recent job function and exposures have been assessed by self-reports. By contrast, mechanical exposure may vary during the years of an occupational career. Working lives of older workers can often be described by a long history of different mechanical work demands and exposures, all of which may contribute to health status later in life. However, asking participants to retrospectively assess physical exposures - such as average level of occupational lifting throughout their working life - may be a source of considerable misclassification of exposure (10). For instance, information on mechanical workload assessed by questionnaire surveys depends on participants' memory, understanding and interpretation (11). In addition, information obtained from questionnaires about several physical exposures seems to be systematically biased by factors such as current disease and socioeconomic status $(12,13)$. To gain new insights into the influence of mechanical work factors on labor market attachment, methods to assess lifelong exposure should be independent of current health status, memory, and life perspective.

The use of an expert-based job exposure matrix (JEM) may provide an appropriate alternative to selfreported data when investigating the relation between mechanical exposures through working life and health related labor market outcomes $(14,15)$. During recent years, several JEM have been constructed to capture exposure to physical working conditions $(14,16)$. However, only few studies have used mechanical exposure JEM, and most of these assess mechanical exposure in relation to development and consequence of different diseases or pain symptoms $(14,17-22)$.

The present study aims to determine the prospective association of cumulative occupational mechanical exposures during working life (from a JEM) with health-related labor market outcomes in older workers (ie, LTSA and disability pension). We hypothesize that cumulative mechanical exposure, defined as occupational lifting, whole-body vibration, and amount of kneeling work, is associated with increased risk of LTSA and disability pension.

\section{Methods}

\section{Study design}

This prospective cohort study merges data from the Copenhagen Aging and Midlife Biobank (CAMB) with a JEM and a national register containing information on sickness absence and disability benefits. The CAMB database was established in 2009-2011 and contains information about biological, psychological, and social factors for individuals between 49-63 years of age. The CAMB cohort was established by merging three existing Danish cohorts - the Metropolit Cohort consists of 10 171 men born in Copenhagen with an age-range of 56-58 years at the CAMB establishment (23); the Copenhagen Perinatal Cohort consists of 8102 men and women born at the National University Hospital in Copenhagen in 1959-1961, ie, an age-range of 49-52 years at the CAMB establishment (24); the Danish Longitudinal Study on Work, Unemployment, and Health consists of 11082 men and women, born 1949 and 1959 - constituting a random sample of the Danish population in 1999 - with an agerange of 50-53 and 60-63 years at the CAMB establishment (25). At the time of the CAMB establishment, 4604 individuals had died or had previously asked to be excluded from cohort follow-ups, which yielded a sample of 24751 persons eligible for invitation into CAMB. Due to lack of resources, 6814 persons ( $28 \%$ of those eligible) were further excluded as they lived in the Western part of Denmark, too far from the study clinic (26). Thus, a total of 17937 persons were invited to participate in the CAMB study, of which 7190 filled in the accompanying questionnaire and 5575 further participated in the clinical examination (26). Individuals not affiliated with the labor market at the point of data collection were not relevant for the present study aim, and only individuals who were on the labor market were included, corresponding to a study population of 5076 older workers. Because not all participants answered all the survey questions, the exact number of participants for each of the following analyses varies. When reporting of the study, the STROBE checklist was followed to ensure transparent and standardized reporting (27). The methods and design have previously been described (28). Table 1 shows the baseline characteristics of the study population.

\section{Ethical approval}

The Danish Data Protection Agency approved the present study (j.nr. 2015-41-4232). The local ethical committee and Danish Data Protection Agency have previously approved the CAMB as a database combining three cohorts: approval No. H-A-2008-126 and No. 201341-1814, respectively (26). Participants were informed about the content and purpose of the CAMB study and gave their written informed consent to participate (26).

\section{Predictor variables}

\section{Retrospective assessment of occupational mechanical} exposure (physical exposure). Occupational mechanical 
Table 1. Baseline characteristics of the study sample including participants ending up on long-term sickness absence (LTSA) and disability pension (DP) within the follow-up period. Assessment of the predictor variables (cumulative mechanical exposures) and the covariates (age, gender, lifestyle and psychosocial work environment throughout working life) are explained in the text. [SD=standard deviation.]

\begin{tabular}{|c|c|c|c|c|c|c|c|c|c|c|c|c|c|c|c|}
\hline & \multirow{2}{*}{\multicolumn{3}{|c|}{$\begin{array}{l}\text { Study sample } \\
(\mathrm{N}=5076)\end{array}$}} & \multicolumn{6}{|c|}{ LTSA during follow-up } & \multicolumn{6}{|c|}{ DP during follow-up } \\
\hline & & & & \multicolumn{3}{|c|}{ No $(\mathrm{N}=4068)$} & \multicolumn{3}{|c|}{ Yes $(\mathrm{N}=970)$} & \multicolumn{3}{|c|}{ No $(\mathrm{N}=4952)$} & \multicolumn{3}{|c|}{ Yes $(\mathrm{N}=85)$} \\
\hline & $\%$ & Mean & SD & $\%$ & Mean & SD & $\%$ & Mean & SD & $\%$ & Mean & SD & $\%$ & Mean & SD \\
\hline Age (years) & & 54.3 & 3.8 & & 54.4 & 3.1 & & 53.8 & 3.5 & & 54.1 & 3.4 & & 54.3 & 3.8 \\
\hline Gender (male) & 70 & & & 71 & & & 62 & & & 70 & & & 65 & & \\
\hline Education (1-5; low-high) & & 3.1 & 1.3 & & 3.2 & 1.3 & & 2.8 & 1.2 & & 3.1 & 1.3 & & 2.4 & 1.1 \\
\hline \multicolumn{16}{|l|}{ Lifestyle } \\
\hline Smoking (yes) & 22 & & & 20 & & & 29 & & & 21 & & & 45 & & \\
\hline BMI $\left(\mathrm{kg} / \mathrm{m}^{2}\right)$ & & 26.0 & 4.1 & & 25.9 & 4.0 & & 26.3 & 4.4 & & 26.0 & 4.1 & & 26.4 & 4.6 \\
\hline Physical activity (1-4; high-low) & & 2.7 & 0.65 & & 2.7 & 0.7 & & 2.8 & 0.6 & & 2.7 & 0.7 & & 3.1 & 0.6 \\
\hline \multicolumn{16}{|l|}{ Cumulative mechanical exposure } \\
\hline Ton-years & & 9.2 & 18.9 & & 8.4 & 18.2 & & 12.5 & 21.3 & & 9.1 & 18.9 & & 16.7 & 24.7 \\
\hline Lifting years & & 8.8 & 18.1 & & 7.9 & 16.8 & & 12.2 & 22.6 & & 8.7 & 18.0 & & 17.4 & 28.7 \\
\hline Kneeling-years & & 4.7 & 12.1 & & 4.4 & 11.4 & & 6.3 & 14.7 & & 4.7 & 12.1 & & 7.4 & 13.7 \\
\hline Vibration-years & & 0.7 & 4.9 & & 0.6 & 5.0 & & 0.7 & 4.2 & & 0.6 & 4.9 & & 1.1 & 4.5 \\
\hline \multicolumn{16}{|l|}{ Psychosocial working conditions (1-5) } \\
\hline Quantitative demands (low-high) & & 3.4 & 1.0 & & 3.4 & 1.0 & & 3.4 & 1.1 & & 3.4 & 1.0 & & 3.4 & 1.0 \\
\hline Influence (high-low) & & 2.2 & 0.8 & & 2.1 & 0.8 & & 2.3 & 0.9 & & 2.1 & 0.8 & & 2.7 & 1.0 \\
\hline Emotional demands (low-high) & & 3.2 & 1.2 & & 3.2 & 1.2 & & 3.2 & 1.2 & & 3.2 & 1.2 & & 3.2 & 1.4 \\
\hline Time pressure (low-high) & & 2.6 & 0.9 & & 2.6 & 0.8 & & 2.6 & 0.8 & & 2.6 & 0.8 & & 2.7 & 0.9 \\
\hline Role conflicts (high-low) & & 3.6 & 0.9 & & 3.6 & 0.9 & & 3.5 & 1.0 & & 3.6 & 0.9 & & 3.5 & 1.0 \\
\hline Possibilities for development (high-low) & & 1.9 & 0.8 & & 1.9 & 0.8 & & 2.0 & 0.8 & & 1.9 & 0.8 & & 2.3 & 0.9 \\
\hline Appreciation (high-low) & & 2.4 & 0.9 & & 2.4 & 0.9 & & 2.5 & 0.9 & & 2.4 & 0.9 & & 2.8 & 1.0 \\
\hline
\end{tabular}

exposures throughout working life were assessed with data from a JEM - the lower-body JEM (10) - that was originally developed for large-scale epidemiological studies of primary hip and knee osteoarthritis (14). The JEM is based on expert judgments of mechanical exposures in 121 homogeneous exposure groups and provide estimates of total load lifted per day and daily frequency of lifting loads weighing $20 \mathrm{~kg}$, as well as hours of exposure to standing/walking, sitting, kneeling/squatting, and whole-body vibration during an 8-hour working day (14, 17). The CAMB questionnaire used for the present study provided information about job history (ie, job titles and length of service for the five longest-held occupations) for each individual in the study population $(18,19)$ and covered in average a total period of 30.6 years per individual worker (31.5 in men and 29.7 in women) (18). Subsequently, job history for each individual worker was coded according to the 1988 revision of the Danish version of the International Standard Classification of Occupations register (DISCO 88) and linked to data from the lower-body JEM. The following mechanical exposures from the JEM were used to assess occupational mechanical exposures throughout working life: lifting, kneeling, and whole body vibration.

Cumulative occupational mechanical exposures were estimated as previously described by Rubak et al (17). In brief, cumulative exposure variables were generated similar to calculation of pack-years are as a measure of cumulated dose of tobacco consumption $(17,29)$. One ton-year was standardized as lifting one ton per working day for one year, one frequent heavy lifting-year as lifting loads weighing $20 \mathrm{~kg}$ ten times per working day for one year, one whole-body vibration year as being exposed to whole-body vibration for one hour of each working day in one year, and one kneeling year as kneeling for one hour each working day in one year $(17,18)$. To investigate the effect of exposure to these mechanical factors, the four occupational mechanical exposures were dichotomized into exposed (those having $\geq 1$ exposure year during working life) and non-exposed (those having no exposure years during working life). To investigate the exposure-response pattern, the four occupational mechanical exposures were categorized as follows: $0,>0-<10,10-<20$, and $\geq 20$ exposure years (17).

\section{Outcome variables}

Data on sickness absence and disability pension were derived from the Register for Evaluation of Marginalization (DREAM), which is a national register containing information on all types of social transfer payments and other basic personal data on all Danish residents $(30,31)$. The outcomes in the present study were loss of labor market attachment due to ill-health, defined by LTSA or disability pension in the 4-6 years follow-up period (ie, baseline measurements were collected from 2009 to 2011 with register follow-up in 2015). In the 
DREAM register, sickness absence is recorded on a weekly basis when the employer is entitled to reimbursement of sickness absence pay. During our follow-up, the period in which the employer received no reimbursement changed from 21 to 30 days of sickness absence (January 2012). To define long-term sickness absence consistently throughout this period, we defined it as sickness absence $>30$ calendar days, corresponding to $\geq 6$ consecutive weeks in DREAM. Disability pension was defined as receiving a disability benefit within the follow-up period. In Denmark, a disability pension is a permanent social benefit for people with a significant and permanent loss of work ability. To obtain disability pension an attempt to increase work ability must have been carried out without success. Individuals with a permanent loss of work ability and working on special terms reflecting permanently reduced work ability were also classified as receiving disability pension (32).

\section{Covariates}

Age, gender, psychosocial work environment throughout working life (described below), physical activity level during leisure, BMI (measured by the clinical personal), smoking and socioeconomic position (described below) were assessed at the time of establishment of the CAMB cohort in 2009-2011.

Psychosocial work environment was assessed by seven dimensions from the Copenhagen Psychosocial Questionnaire (33) that was modified to retrospectively cover the participants' entire working life: (i) quantitative demands, (ii) influence/decision authority, (iii) emotional demands, (iv) time pressure, (v) role conflicts, (vi) possibilities for development, and (vii) rewards/ appreciation.

Socioeconomic position was evaluated by educational level. Education level was categorized into five groups; unskilled, skilled, and short-, medium-, and long education (18).

\section{Statistical methods}

The Cox proportional hazard model $(34,35)$, censoring for competing events, was used for modelling the risk of register based LTSA and disability pension during the 4-6 year follow-up period. When individuals had an onset of LTSA and disability pension within the followup period, the survival times were non-censored and referred to as event times. In the analyses, we employed a competing risk approach where we censored for all competing events of permanent drop-out from the labor market within the follow-up period. For instance, in the analysis with disability pension as outcome, we censored for statutory retirement, early retirement, emigration, and death. Importantly, individuals staying at the labor market past 65 years (statutory retirement age) were kept in the analyses. To receive early retirement benefits in Denmark one must fulfill certain criteria: (i) be a member of an unemployment insurance fund, (ii) have paid retirement contribution for 30 years, and (iii) be entitled to unemployment benefits, meaning that one must be available to the labor market, not be sick or unable to take on a job. Furthermore, one must have reached the early retirement age: with the adoption of the early retirement reform in 2011, this limit is gradually shifted to 64 years for persons born in 1959 or later and 65 years for persons born in 1963 or later. Analyses were carried out separately for each of the four occupational mechanical exposures and step-wise adjusted for potential confounders to study the influence of confounders on the associations: the crude model illustrates the unadjusted estimates, model 1 was controlled for age, gender and education, model 2 was additionally adjusted for lifestyle (BMI, smoking, physical activity), and model 3 was additionally adjusted for psychosocial work environment throughout working life. To statistically test for the existence of exposure-response relationships between the mechanical exposures and outcomes, trendtests were performed by including the four predictor variables (ie, ton-years, lifting-years, vibration-years and kneeling-years) as continuous variables in the Cox proportional hazard model. Because occupational lifting may affect men and women differently (eg, men have higher muscle strength than women in average) we performed exploratory gender-stratified analyses for the dichotomized ton- and lifting-year variables.

The estimation method was maximum likelihood and the results are reported as hazard ratios (HR) with $95 \%$ confidence intervals $(\mathrm{CI})$.

\section{Results}

Of the total study population, exposure to ton-, liftingand kneeling-years during the occupational career was $50.0 \%, 49.3 \%$ and $35.6 \%$, respectively. Specifically, exposure to $\geq 20$ ton- and lifting-years during the working lives was $14.7 \%$ and $15.6 \%$, respectively.

During the follow-up period the following number of outcome events occurred: 970 persons $(19.3 \%)$ had at least one episode of LTSA; 85 persons (1.7\%) received disability pension; $538(10.7 \%)$ received early retirement benefit; $529(10.4 \%)$ received state pension.

\section{Occupational mechanical exposure}

Table 2 shows the results for the association between cumulative ton-, lifting-, kneeling-, and vibration-years (ie, exposure-response pattern) during an occupational 
career and risk of LTSA. In the fully adjusted model, being exposed to ton-, lifting-, kneeling-, and vibrationyears during working life (dichotomized exposure) predicted risk of LTSA. Highly statistically significant exposure-response associations were observed between number of ton-years and LTSA $(\mathrm{P}<0.0001)$, number of lifting-years and LTSA $(\mathrm{P}<0.0001)$, and number of kneeling-years and LTSA $(\mathrm{P}<0.0001)$. We did not observe an exposure-response relation between vibration-years and LTSA $(\mathrm{P}=0.51)$.

Table 3 shows the results for the association between cumulative ton-, lifting-, kneeling-, and vibration-years (ie, exposure-response pattern) during an occupational career and risk of disability pension. In the fully adjusted model, only lifting-years significantly predicted risk of disability pension (dichotomized exposure). We did not observe any statistically significant exposure-response relation between any of the mechanical exposures and disability pension (all $\mathrm{P}>0.14$ ). For ton-years and liftingyears, those with $<10$ years of exposure had an increased risk of disability pension. None of the remaining cumulative mechanical occupational exposures were significantly associated with risk of disability pension in the fully adjusted model.

\section{Exploratory analyses}

The exploratory analyses stratified by gender showed that being exposed to ton- and lifting-years during working life statistical significantly predicted risk of LTSA for both men (HR 1.38 95\% CI 1.13-1.69; HR $1.3895 \%$ CI 1.13-1.68, respectively) and women (HR 1.27 95\% CI 1.01-1.58; HR 1.26 95\% CI 1.01-1.57, respectively). In contrast, being exposed to ton- and lifting-years during working life did not significantly predict risk of disability pension for men (HR 1.59 95\% CI 0.76-3.35; HR $1.6195 \%$ CI 0.76-3.38, respectively) or women (HR $1.6895 \%$ CI 0.73-3.91; HR $1.7895 \%$ CI $0.76-4.14$, respectively).

\section{Discussion}

Cumulative occupational mechanical exposures during working life were associated with future LTSA. Specifically, an exposure-response relation was observed between ton-, lifting-, and kneeling-years and LTSA.

Table 2. The association between cumulative ton-, lifting-, kneeling-, and vibration-years (i.e. exposure-response pattern) during an occupational career and risk of long-term sickness absence. "No" refers to unexposed during working life ( 0 years) and "Yes" refers to exposed during working life (>0 years). [HR=hazard ratio; $95 \% \mathrm{Cl}=95 \%$ confidence intervals.]

\begin{tabular}{|c|c|c|c|c|c|c|c|c|c|c|}
\hline \multirow{3}{*}{$\begin{array}{l}\text { Exposure } \\
\text { years }\end{array}$} & \multirow[b]{3}{*}{$\mathrm{N}$} & \multirow[b]{3}{*}{$\%$} & \multirow{2}{*}{\multicolumn{2}{|c|}{ Crude }} & \multicolumn{6}{|c|}{ Long-term sickness absence } \\
\hline & & & & & \multicolumn{2}{|c|}{ Model $1^{a}$} & \multicolumn{2}{|c|}{ Model $2^{b}$} & \multicolumn{2}{|c|}{ Model $3^{c}$} \\
\hline & & & $\mathrm{HR}$ & $95 \% \mathrm{Cl}$ & $\mathrm{HR}$ & $95 \% \mathrm{Cl}$ & $\mathrm{HR}$ & $95 \% \mathrm{Cl}$ & $\mathrm{HR}$ & $95 \% \mathrm{Cl}$ \\
\hline \multicolumn{11}{|l|}{ Ton-years } \\
\hline No & 2483 & 50.04 & 1 & & 1 & & 1 & & 1 & \\
\hline Yes & 2479 & 49.96 & 1.59 & $1.39-1.81$ & 1.49 & $1.29-1.71$ & 1.44 & & 1.35 & $1.17-1.57$ \\
\hline$>0-<10$ & 1208 & 24.35 & 1.40 & $1.20-1.65$ & 1.37 & $1.16-1.61$ & 1.33 & $1.13-1.57$ & 1.26 & $1.06-1.49$ \\
\hline $10-<20$ & 542 & 10.92 & 1.66 & $1.36-2.03$ & 1.56 & $1.27-1.93$ & 1.50 & $1.21-1.85$ & 1.40 & $1.24-1.75$ \\
\hline$\geq 20$ & 729 & 14.69 & 1.83 & $1.54-2.18$ & 1.73 & $1.42-2.10$ & 1.66 & $1.37-2.03$ & 1.56 & $1.28-1.91$ \\
\hline \multicolumn{11}{|c|}{ Lifting-years } \\
\hline No & 2515 & 50.69 & 1 & & 1 & & 1 & & 1 & \\
\hline Yes & 2447 & 49.31 & 1.58 & $1.38-1.80$ & 1.49 & $1.30-1.72$ & 1.44 & $1.25-1.66$ & 1.35 & $1.17-1.56$ \\
\hline$>0-<10$ & 1164 & 23.46 & 1.37 & $1.16-1.61$ & 1.34 & $1.14-1.58$ & 1.31 & $1.10-1.54$ & 1.24 & $1.04-1.46$ \\
\hline $10-<20$ & 507 & 10.22 & 1.80 & $1.47-2.20$ & 1.69 & $1.36-2.09$ & 1.59 & $1.28-1.98$ & 1.45 & $1.16-1.82$ \\
\hline$\geq 20$ & 776 & 15.64 & 1.76 & $1.48-2.09$ & 1.69 & $1.40-2.05$ & 1.66 & $1.36-2.01$ & 1.55 & $1.27-1.89$ \\
\hline \multicolumn{11}{|c|}{ Kneeling-years } \\
\hline No & 3194 & 64.37 & 1 & & 1 & & 1 & & 1 & \\
\hline Yes & 1768 & 35.63 & 1.42 & $1.25-1.62$ & 1.39 & $1.20-1.60$ & 1.34 & $1.16-1.55$ & 1.28 & $1.10-1.48$ \\
\hline$>0-<10$ & 1131 & 22.79 & 1.40 & $1.20-1.62$ & 1.32 & $1.13-1.54$ & 1.26 & $1.08-1.48$ & 1.20 & $1.02-1.41$ \\
\hline $10-<20$ & 205 & 4.13 & 1.34 & $0.99-1.82$ & 1.30 & $0.95-1.78$ & 1.26 & $0.92-1.73$ & 1.05 & $0.76-1.46$ \\
\hline$\geq 20$ & 432 & 8.71 & 1.53 & $1.25-1.89$ & 1.73 & $1.37-2.17$ & 1.73 & $1.38-2.18$ & 1.76 & $1.39-2.22$ \\
\hline \multicolumn{11}{|c|}{ Vibration-years } \\
\hline No & 4469 & 90.06 & 1 & & 1 & & 1 & & 1 & \\
\hline Yes & 493 & 9.94 & 1.40 & $1.15-1.69$ & 1.34 & $1.10-1.64$ & 1.30 & $1.07-1.59$ & 1.25 & $1.03-1.54$ \\
\hline$>0-<10$ & 427 & 8.61 & 1.44 & $1.18-1.86$ & 1.38 & $1.12-1.69$ & 1.33 & $1.08-1.64$ & 1.25 & $1.01-1.56$ \\
\hline $10-<20$ & 35 & 0.71 & 0.88 & $0.37-2.12$ & 0.96 & $0.40-2.33$ & 0.91 & $0.38-2.20$ & 0.95 & $0.39-2.30$ \\
\hline$\geq 20$ & 31 & 0.62 & 1.34 & $0.67-2.70$ & 1.25 & $0.62-2.52$ & 1.30 & $0.65-2.62$ & 1.65 & $0.81-3.33$ \\
\hline
\end{tabular}

\footnotetext{
a Adjusted for age, gender and education.
}

${ }^{\mathrm{b}}$ Model 1 + lifestyle (BMI, smoking, leisure physical activity).

c Model $2+$ psychosocial work environment throughout working life. 
Table 3. The association between cumulative ton-, lifting-, kneeling-, and vibration-years (i.e. exposure-response pattern) during an occupational career and risk of disability pension. "No" refers to unexposed during working life (0 years) and "Yes" refers to exposed during working life (>0 years). [HR=hazard ratio; $95 \% \mathrm{Cl}=95 \%$ confidence intervals.]

\begin{tabular}{|c|c|c|c|c|c|c|c|c|c|c|}
\hline \multirow{3}{*}{$\begin{array}{l}\text { Exposure } \\
\text { years }\end{array}$} & \multirow[b]{3}{*}{$\mathrm{N}$} & \multirow[b]{3}{*}{$\%$} & \multirow{2}{*}{\multicolumn{2}{|c|}{ Crude }} & \multicolumn{6}{|c|}{ Disability pension } \\
\hline & & & & & \multicolumn{2}{|c|}{ Model $1{ }^{\text {a }}$} & \multicolumn{2}{|c|}{ Model $2{ }^{b}$} & \multicolumn{2}{|c|}{ Model $3^{c}$} \\
\hline & & & $\mathrm{HR}$ & $95 \% \mathrm{Cl}$ & $\mathrm{HR}$ & $95 \% \mathrm{Cl}$ & $\mathrm{HR}$ & $95 \% \mathrm{Cl}$ & $\mathrm{HR}$ & $95 \% \mathrm{Cl}$ \\
\hline \multicolumn{11}{|l|}{ Ton-years } \\
\hline No & 2483 & 50.04 & 1 & & 1 & & 1 & & 1 & \\
\hline Yes & 2479 & 49.96 & 2.84 & $1.73-4.67$ & 2.09 & $1.24-3.53$ & 1.99 & $1.16-3.41$ & 1.70 & $0.98-2.96$ \\
\hline$>0-<10$ & 1208 & 24.35 & 2.64 & $1.49-4.68$ & 2.19 & $1.23-3.89$ & 2.18 & $1.22-3.93$ & 1.92 & $1.06-3.47$ \\
\hline $10-<20$ & 542 & 10.92 & 2.99 & $1.45-5.79$ & 2.03 & $1.00-4.13$ & 1.77 & $0.85-3.69$ & 1.51 & $0.74-3.22$ \\
\hline$\geq 20$ & 729 & 14.69 & 3.12 & $1.68-5.81$ & 1.95 & $0.99-3.82$ & 1.72 & $0.90-3.55$ & 1.44 & $0.72-2.91$ \\
\hline \multicolumn{11}{|c|}{ Lifting-years } \\
\hline No & 2515 & 50.69 & 1 & & 1 & & 1 & & 1 & \\
\hline Yes & 2447 & 49.31 & 2.91 & $1.77-4.79$ & 2.18 & $1.29-3.68$ & 2.07 & $1.21-3.56$ & 1.75 & $1.01-3.04$ \\
\hline$>0-<10$ & 1164 & 23.46 & 2.47 & $1.38-4.44$ & 2.07 & $1.15-3.74$ & 2.07 & $1.13-3.77$ & 1.89 & $1.04-3.46$ \\
\hline $10-<20$ & 507 & 10.22 & 3.64 & $1.88-7.06$ & 2.69 & $1.36-5.32$ & 2.31 & $1.14-4.68$ & 1.76 & $0.84-3.69$ \\
\hline$\geq 20$ & 776 & 15.64 & 3.11 & $1.69-5.73$ & 2.00 & $1.02-3.92$ & 1.90 & $0.96-3.77$ & 1.47 & $0.73-2.97$ \\
\hline \multicolumn{11}{|c|}{ Kneeling-years } \\
\hline No & 3194 & 64.37 & 1 & & 1 & & 1 & & 1 & \\
\hline Yes & 1768 & 35.63 & 1.90 & $1.23-2.95$ & 1.41 & $0.88-2.26$ & 1.30 & $0.81-2.09$ & 1.13 & $0.70-1.83$ \\
\hline$>0-<10$ & 1131 & 22.79 & 1.80 & $1.09-2.98$ & 1.38 & $0.82-2.32$ & 1.21 & $0.71-2.06$ & 1.03 & $0.60-1.77$ \\
\hline $10-<20$ & 205 & 4.13 & 1.60 & $0.57-4.48$ & 1.11 & $0.39-3.15$ & 1.03 & $0.36-2.93$ & 0.88 & $0.31-2.53$ \\
\hline$\geq 20$ & 432 & 8.71 & 2.31 & $1.21-4.41$ & 1.69 & $0.84-3.42$ & 1.79 & $0.89-3.61$ & 1.75 & $0.85-3.61$ \\
\hline \multicolumn{11}{|c|}{ Vibration-years } \\
\hline No & 4469 & 90.06 & 1 & & 1 & & 1 & & 1 & \\
\hline Yes & 493 & 9.94 & 2.31 & $1.33-3.99$ & 1.89 & $1.09-2.29$ & 1.56 & $0.89-2.76$ & 1.41 & $0.79-2.50$ \\
\hline$>0-<10$ & 427 & 8.61 & 2.34 & $1.31-4.17$ & 1.93 & $1.09-3.45$ & 1.57 & $0.86-2.85$ & 1.38 & $0.75-2.53$ \\
\hline $10-<20$ & 35 & 0.71 & 2.00 & $0.28-14.44$ & 1.59 & $0.22-11.60$ & 1.37 & $0.19-9.98$ & 1.37 & $0.19-10.08$ \\
\hline$\geq 20$ & 31 & 0.62 & 2.23 & $0.31-16.04$ & 1.62 & $0.22-11.60$ & 1.73 & $0.24-12.58$ & 1.96 & $0.27-14.49$ \\
\hline
\end{tabular}

a Adjusted for age, gender and education.

${ }^{\mathrm{b}}$ Model 1 + lifestyle (BMI, smoking, leisure physical activity).

${ }^{c}$ Model 2 + psychosocial work environment throughout working life.

Lifting-years, but not the other mechanical exposures, were associated with increased risk of disability pension.

\section{Strengths and limitations}

Determining cumulative mechanical exposure through working life using a JEM is both a strength and a limitation of the study. Using a JEM strengthens the study due to elimination of common biases associated with self-reported occupational mechanical exposure. For example, mechanical exposures assessed retrospectively by self-reports may be especially prone to recall bias and affected by individuals current health status, mental state and work environment $(12,13)$. Using a JEM is a limitation because it provides a very crude measure of cumulative occupational mechanical exposure through an occupational career. In the JEM, mechanical occupational exposures were linked to job titles in homogenous exposure groups (18), but large individual exposure differences exist within each job group $(17,36,37)$. Hence, any exposure contrast within job groups would be reduced with the possibility of underestimating true associations (17). In addition, an expert evaluation of mechanical exposure in a given occupation in 2010 (when the lower-body JEM was developed) may not be valid for the exposure level in the same occupation in the 1970s. For instance, it has previously been shown that physical workloads decreased among men from 1970 to 1993, whereas it increased among women in the same time period (38). Furthermore, by using a JEM exposure within occupational groups is assumed to remain stable throughout life, whereas work tasks and physical demands within these job groups may not be similar for 20- and 60-year old workers. As working lives often can be described by a long history of different occupational mechanical work demands and exposures, future studies should employ a more detailed analytical approach to investigate if specific periods of the working life are more important than others in relation to future LTSA and disability pension.

The low response rate of the CAMB study suggests that participants are a somewhat selected group. To evaluate the effect of this possible bias, Avlund et al (26) compared participants and non-participants by linking data from the CAMB study with national registers and found that educational level did not differ substantially between participants and non-participants. However, a greater proportion of the participants were employed 
compared to non-participants suggesting that the participants may represent a socially selected group. In Denmark, one needs a referral from a general practitioner for all non-acute medical examinations and treatment at hospitals and visits to specialists and physical therapists. By using number of contacts with general practitioners during the year of 2009 as a proxy measure for general health, the non-response analysis showed that the health of the participants and non-participants were nearly the same, suggesting that the two groups are comparable in terms of health (26). Despite these overall similarities in general health and educational level between participants and non-participants, the healthy worker effect could still be a source of confounding bias in the present study. Hence, it cannot be ruled out that those with the longest history of physically demanding work could already be outside the workforce when the present study was initiated (19).

The low number of cases for disability pension is an important limitation to the study. Thus, a plausible explanation for the non-significant associations between accumulated mechanical exposures and disability pension, despite numerically high risk estimates, could be due to insufficient statistical power. In line with this, the number of participants exposed to vibration for $>10$ years are limited and the observed high - but nonsignificant - risk estimates may also be explained by a lack of statistical power.

A strength of the study is the use of data on sickness absence and disability pension from the DREAM register, which has high reliability because all transfer payments are systematically recorded (30). Hence, DREAM makes it possible to assess labor market attachment that is free from potential bias from self-reported LTSA and disability pension. Additionally, by using register data on labor market attachment, common methods variance (ie, associations between exposure and outcome due to same assessment methods) as well as recall bias with regard to outcome ascertainment was eliminated (39). Another strength is the thoroughly constructed CAMB questionnaire, providing the opportunity to control for potential confounders and mediators, which is not possible in studies only using registers. However, asking participants to combine psychosocial exposures during their working life in a single number for their average level of influence at work and role conflicts (among others) could be prone to potential bias, in particular recall bias. Even though few psychosocial JEM have been developed, employing such a method would probably have given a more detailed and unbiased estimate of psychosocial working conditions throughout working life.

Finally, the large sample size and the recruitment of older individuals from the general population is a strength of the study. However, the age definition of older workers is not generally agreed on and a broad range of ages between $40-65$ years are used by different organizations, researchers and agencies $(40,41)$. As an example, 45 years have been used an occupational health research as the base criterion for the "aging worker" because it provides better opportunities for preventive strategies $(40,41)$. The applicability of the results to other countries with different arrangements of sickness absence benefits, disability pensions, and labor market protection needs to be further investigated. For instance, van der Wel and coworkers (2012) concluded that the welfare system of Scandinavian countries are better at protecting against non-employment due to illness than other systems (42). The generalizability of the present study therefore seems to apply to workers in a welfare state within the age range of 49-63 years.

\section{Interpretation of results}

The risk of LTSA increased in an exposure-response association with the number of years with occupational lifting and kneeling. In the fully adjusted model, both long term ( $\geq 20$ years), moderate term $(10-<20$ years) and short term $(<10$ years $)$ exposure to both lifting one ton per working day (ie, ton-years) and lifting loads weighing $20 \mathrm{~kg}$ ten times per working day (ie, liftingyears) predicted risk of LTSA. These findings elaborate on previous research investigating the association between self-rated mechanical exposure in participants' latest job function and LTSA. Specifically, factors such as heavy lifting and kneeling work have previously been related to sickness absence (6-9). To our knowledge, only one study has investigated the association between occupational mechanical exposure assessed by a JEM and labor market outcomes (20). That study observed an increased risk of LTSA among individuals with high mechanical exposure in their latest job function compared to those with low mechanical exposure. The present study provides new information on the exposure-response patterns by showing that the level of exposure to occupational mechanical factors throughout a working career - such as lifting and kneeling work are increasingly associated with LTSA at old age.

In the analysis with disability pension as outcome, only being exposed to heavy and frequent lifting (ie, lifting-years) during working life was a predictive factor (table 3). However, in the subsequent analysis involving cumulative mechanical occupational exposures during working life, only a short period of exposure ( $<10$ years) to heavy and frequent lifting was significantly associated with disability pension. However, all mechanical exposures significantly predicted risk of disability pension in the crude unadjusted model (table 3 ). Thus, adjusting for potential confounders - such as lifestyle factors, education and psychosocial work environment - decreased the risk estimates substantially. 
Over-adjustment can lead to underestimation of risk estimates and may in the present study partially explain the lack of significant findings in the final model 3. If the effect of high mechanical exposure on disability pension is mediated by some of the covariates - such as lifestyle and psychosocial work environment - adjusting for these can be considered an over adjustment. For instance, lifestyle factors in mid-life (BMI, physical activity at leisure, smoking) were considered potential confounders, eg, if lifestyle in mid-life is seen as a representative measure of previous lifestyle, it could have influenced the duration a worker is able to meet high physical work demands, thereby affecting cumulative mechanical exposure during working life (19). However, it can also be considered a mediator between hard physical work and LTSA and disability pension, eg, hard physical work may lead to less activity during leisure. The step-wise addition of possible confounders indicated that both lifestyle and psychosocial work environment influenced the association between cumulative mechanical occupational exposures and disability pension. In addition, controlling for education might also be an over-adjustment as people with no or short education often have jobs with manual work. However, education is associated with both the predictor and the outcome and therefore seems to be an important confounder. In particular, it seems reasonable to control for education in a study employing data from a JEM in which exposure is based on job titles (which is also related to education).

Despite the possibility of over-adjustment, the risk estimates for disability pension were generally increased among the exposed compared with the non-exposed (ie, no exposure years), A somewhat similar methodological challenge was presented in a recent study by Sommer et al (20) showing that high occupational mechanical exposure per se (assessed by upper- and lower-body JEM) were associated with two-fold risk of sickness absence and a similar, but insignificant increase in the risk of permanent work disability (ie, disability pension and flexible job subsidies). They explained their statistically non-significant results on disability pension by low statistical power: during 104 weeks of follow-up, 119 participants $(0.5 \%)$ were registered with transition to permanent work disability. In contrast, previous studies employing self-rated mechanical exposures have shown an association between physical workload in participants' latest job function and disability pension $(43,44)$.

It has previously been established that poor health is an important determinant of transition into sickness absence and disability pension (20,45-49). Specifically, health problems such as musculoskeletal disorders, depression and anxiety predicts the risk of both LTSA and disability pension $(20,50,51)$. The DREAM register holds no information on diagnoses, and we could therefore not investigate the association between specific diseases and LTSA and disability pension. However, the results from the present study are somewhat comparable with a recent study showing that musculoskeletal pain was associated with sickness absence and permanent work disability, and that high mechanical exposure at work increased this risk even further (20). On the other hand, Robroek et al (2013) found that poor health and lack of job control played a statistical significant role in labor market exit, whereas having a physically demanding job did not (47).

By calculating the cumulative mechanical exposure through working life, the present study contributes to the literature by providing an alternative approach to elucidate the association between mechanical exposure and use of social security benefits. With the strengths and weaknesses associated with employing an expertbased JEM or workers self-ratings to assess occupational mechanical exposure there is no conclusive answer to which method is most accurate, reliable and valid. Instead, the two different approaches should be considered complementary perspectives, which together help to illuminate the influence of hard physical work on health related labor market outcomes. With that in mind, the present study supports existing knowledge, ie, that a reduction of mechanical work exposures is needed to prevent loss of labor market attachment ( 7 , $8,44)$. In particular, policymakers should put greater consideration into work history in their effort to keep older workers employed, and workplaces should strive to find new ways of retaining older workers, especially if they have been working in physically demanding jobs their entire life.

\section{Concluding remarks}

Cumulative occupational mechanical exposures predicted risk of future LTSA. Specifically, both ton-, lifting- and kneeling-years showed an exposure-response association with risk of LTSA. Of the mechanical exposures, only lifting-years were significantly associated with disability pension.

\section{Acknowledgements}

CAMB has been supported by a generous grant from the Velux Foundation (VELUX26145 and 31539). The authors thank the staff at the Department of Public Health and the National Research Centre for the Working Environment, who undertook the data collection. Further thanks to Kirsten Avlund $\dagger$, Helle Bruunsgaard, Nils-Erik Fiehn, Poul Holm-Pedersen, Rikke Lund and Merete Osler, who initiated and established the Copenhagen Aging and Midlife Biobank from 2009-2011. The 
authors acknowledge the crucial role of the initiators and steering groups of the Metropolit Cohort, the Copenhagen Perinatal Cohort and the Danish Longitudinal Study on Work, Unemployment and Health.

This study was supported by a grant from the Danish Working Environment Research Fund (Grant no. 20130068772/3).

The authors declare no competing interests.

\section{References}

1. Gjesdal S, Haug K, Ringdal P, Maeland JG, Hagberg J, Røraas T, et al. Sickness absence with musculoskeletal or mental diagnoses, transition into disability pension and all-cause mortality: a 9-year prospective cohort study. Scand J Public Health. 2009 Jun;37(4):387-94. https://doi. org/10.1177/1403494809103994

2. Karlsson NE, Carstensen JM, Gjesdal S, Alexanderson KAE. Risk factors for disability pension in a population-based cohort of men and women on long-term sick leave in Sweden. Eur J Public Health. 2008 Jun;18(3):224-31. https://doi. org/10.1093/eurpub/ckm128

3. Kivimäki M, Forma P, Wikström J, Halmeenmäki T, Pentti J, Elovainio M, et al. Sickness absence as a risk marker of future disability pension: the 10-town study. J Epidemiol Community Health. 2004 Aug;58(8):710-1. https://doi.org/10.1136/ jech.2003.015842

4. Vingård E, Alexanderson K, Norlund A. Swedish Council on Technology Assessment in Health Care (SBU). Chapter 9. Consequences of being on sick leave. Scand J Public Health Suppl. 2004;63:207-15. https://doi. org/10.1080/14034950410021899

5. Goetzel RZ, Long SR, Ozminkowski RJ, Hawkins K, Wang S, Lynch W. Health, absence, disability, and presenteeism cost estimates of certain physical and mental health conditions affecting U.S. employers. J Occup Environ Med. 2004 Apr;46(4):398-412. https://doi.org/10.1097/01. jom.0000121151.40413.bd

6. Lund T, Labriola M, Christensen KB, Bültmann U, Villadsen E. Physical work environment risk factors for long term sickness absence: prospective findings among a cohort of 5357 employees in Denmark. BMJ. 2006 Feb 25;332(7539):449-52. https://doi.org/10.1136/bmj.38731.622975.3A

7. Sterud T. Work-related mechanical risk factors for long-term sick leave: a prospective study of the general working population in Norway. Eur J Public Health. 2014 Feb;24(1):111-6. https://doi.org/10.1093/eurpub/ckt072

8. Andersen LL, Fallentin N, Thorsen SV, Holtermann A. Physical workload and risk of long-term sickness absence in the general working population and among blue-collar workers: prospective cohort study with register follow-up. Occup Environ Med. 2016 Apr;73(4):246-53. https://doi. org/10.1136/oemed-2015-103314
9. Bongers PM, Boshuizen $\mathrm{HC}$, Hulshof CT, Koemeester AP. Long-term sickness absence due to back disorders in crane operators exposed to whole-body vibration. Int Arch Occup Environ Health. 1988;61(1-2):59-64. https://doi. org/10.1007/BF00381608

10. Møller A. Validity of Workers' Self-Reports. Evaluation of a Question Assessing Lifetime Exposure to Occupational Physical Activity. Br J Med Med Res. 2012 Jan 10;2(4):53652. https://doi.org/10.9734/BJMMR/2012/1607

11. Lagersted-Olsen J, Korshøj M, Skotte J, Carneiro IG, Søgaard K, Holtermann A. Comparison of objectively measured and self-reported time spent sitting. Int J Sports Med. 2014 Jun;35(6):534-40.

12. Wiktorin C, Karlqvist L, Winkel J. Validity of self-reported exposures to work postures and manual materials handling. Stockholm MUSIC I Study Group. Scand J Work Environ Health. 1993 Jun;19(3):208-14. https://doi.org/10.5271/ sjweh. 1481

13. Sabia S, van Hees VT, Shipley MJ, Trenell MI, HaggerJohnson G, Elbaz A, et al. Association between questionnaireand accelerometer-assessed physical activity: the role of sociodemographic factors. Am J Epidemiol. 2014 Mar 15;179(6):781-90. https://doi.org/10.1093/aje/kwt330

14. Rubak TS, Svendsen SW, Andersen JH, Haahr JPL, Kryger A, Jensen LD, et al. An expert-based job exposure matrix for large scale epidemiologic studies of primary hip and knee osteoarthritis: the Lower Body JEM. BMC Musculoskelet Disord. 2014;15:204. https://doi.org/10.1186/1471-2474-15204

15. Teschke K, Olshan AF, Daniels JL, De Roos AJ, Parks CG, Schulz M, et al. Occupational exposure assessment in casecontrol studies: opportunities for improvement. Occup Environ Med. 2002 Sep;59(9):575-593; discussion 594. https://doi. org/10.1136/oem.59.9.575

16. Dalbøge A, Hansson G-Å, Frost P, Andersen JH, HeilskovHansen T, Svendsen SW. Upper arm elevation and repetitive shoulder movements: a general population job exposure matrix based on expert ratings and technical measurements. Occup Environ Med. 2016 Aug;73(8):553-60. https://doi. org/10.1136/oemed-2015-103415

17. Rubak TS, Svendsen SW, Søballe K, Frost P. Total hip replacement due to primary osteoarthritis in relation to cumulative occupational exposures and lifestyle factors: a nationwide nested case-control study. Arthritis Care Res. 2014 Oct;66(10):1496-505. https://doi.org/10.1002/acr.22326

18. Møller A, Reventlow S, Hansen AM, Andersen LL, Siersma V, Lund R, et al. Does a history of physical exposures at work affect hand-grip strength in midlife? A retrospective cohort study in Denmark. Scand J Work Environ Health. 2013 May 10; https://doi.org/10.5271/sjweh.3368

19. Møller A, Reventlow S, Hansen ÅM, Andersen LL, Siersma V, Lund R, et al. Does physical exposure throughout working life influence chair-rise performance in midlife? A retrospective cohort study of associations between work and physical function in Denmark. BMJ Open. 2015 Nov 4;5(11):e009873. https://doi.org/10.1136/bmjopen-2015-009873 
20. Sommer TG, Svendsen SW, Frost P. Sickness absence and permanent work disability in relation to upper- and lower-body pain and occupational mechanical and psychosocial exposures. Scand . Work Environ Health. 2016 Jun 1;42(6):481-9. https:// doi.org/10.5271/sjweh. 3600

21. Vad MV, Frost P, Svendsen SW. Occupational mechanical exposures and reoperation after first-time inguinal hernia repair: a prognosis study in a male cohort. Hernia J Hernias Abdom Wall Surg. 2015 Dec;19(6):893-900. https://doi. org/10.1007/s10029-014-1339-0

22. Vad MV, Frost P, Bay-Nielsen M, Svendsen SW. Impact of occupational mechanical exposures on risk of lateral and medial inguinal hernia requiring surgical repair. Occup Environ Med. 2012 Nov;69(11):802-9. https://doi. org/10.1136/oemed-2012-100787

23. Osler M, Lund R, Kriegbaum M, Christensen U, Andersen A-MN. Cohort profile: the Metropolit 1953 Danish male birth cohort. Int J Epidemiol. 2006 Jun;35(3):541-5. https://doi. org/10.1093/ije/dyi300

24. Zachau-Christiansen B. Development during the first year of life. Helsingør, Denmark: Poul Andersens Forlag; 1972.

25. Christensen U, Lund R, Damsgaard MT, Holstein BE, Ditlevsen S, Diderichsen F, et al. Cynical hostility, socioeconomic position, health behaviors, and symptom load: a cross-sectional analysis in a Danish population-based study. Psychosom Med. 2004 Aug;66(4):572-7. https://doi. org/10.1097/01.psy.0000126206.35683.d1

26. Avlund K, Osler M, Mortensen EL, Christensen U, Bruunsgaard $\mathrm{H}$, Holm-Pedersen P, et al. Copenhagen Aging and Midlife Biobank (CAMB): an introduction. J Aging Health. 2014 Feb;26(1):5-20. https://doi.org/10.1177/0898264313509277

27. von Elm E, Altman DG, Egger M, Pocock SJ, Gøtzsche PC, Vandenbroucke JP, et al. Strengthening the Reporting of Observational Studies in Epidemiology (STROBE) statement: guidelines for reporting observational studies. BMJ. 2007 Oct 20;335(7624):806-8. https://doi.org/10.1136/ bmj.39335.541782.AD

28. Sundstrup E, Hansen ÅM, Mortensen EL, Poulsen OM, Clausen T, Rugulies R, et al. Influence of physical and psychosocial work environment throughout life and physical and cognitive capacity in midlife on labor market attachment among older workers: study protocol for a prospective cohort study. BMC Public Health. 2016;16:629. https://doi. org/10.1186/s12889-016-3290-8

29. Lubin JH, Caporaso N, Wichmann HE, Schaffrath-Rosario A, Alavanja MCR. Cigarette smoking and lung cancer: modeling effect modification of total exposure and intensity. Epidemiol Camb Mass. 2007 Sep;18(5):639-48. https://doi.org/10.1097/ EDE.0b013e31812717fe

30. Hjollund NH, Larsen FB, Andersen JH. Register-based followup of social benefits and other transfer payments: accuracy and degree of completeness in a Danish interdepartmental administrative database compared with a population-based survey. Scand J Public Health. 2007;35(5):497-502. https:// doi.org/10.1080/14034940701271882
31. Lund T, Kivimäki M, Labriola M, Villadsen E, Christensen $\mathrm{KB}$. Using administrative sickness absence data as a marker of future disability pension: the prospective DREAM study of Danish private sector employees. Occup Environ Med. 2008 Jan;65(1):28-31. https://doi.org/10.1136/oem.2006.031393

32. Pedersen J, Bjorner JB, Burr H, Christensen KB. Transitions between sickness absence, work, unemployment, and disability in Denmark 2004-2008. Scand J Work Environ Health. 2012 Nov;38(6):516-26. https://doi.org/10.5271/sjweh.3293

33. Pejtersen JH, Kristensen TS, Borg V, Bjorner JB. The second version of the Copenhagen Psychosocial Questionnaire. Scand J Public Health. 2010 Feb;38(3 Suppl):8-24. https://doi. org/10.1177/1403494809349858

34. Andersen LL, Clausen T, Persson R, Holtermann A. Doseresponse relation between perceived physical exertion during healthcare work and risk of long-term sickness absence. Scand J Work Environ Health [Internet] . 2012 Jun 19 [cited 2012 Jul 26]; Available from: http://www.ncbi.nlm.nih.gov/ pubmed/22714069

35. Andersen LL, Mortensen OS, Hansen JV, Burr H. A prospective cohort study on severe pain as a risk factor for long-term sickness absence in blue- and white-collar workers. Occup Environ Med. 2011 Aug;68(8):590-2. https://doi. org/10.1136/oem.2010.056259

36. Mannetje A 't, Kromhout $H$. The use of occupation and industry classifications in general population studies. Int $\mathrm{J}$ Epidemiol. 2003 Jun;32(3):419-28. https://doi.org/10.1093/ ije/dyg080

37. Kauppinen TP, Mutanen PO, Seitsamo JT. Magnitude of misclassification bias when using a job-exposure matrix. Scand J Work Environ Health. 1992 Apr;18(2):105-12. https:// doi.org/10.5271/sjweh.1604

38. Torgén M, Kilbom A. Physical work load between 1970 and 1993--did it change? Scand J Work Environ Health. 2000 Apr;26(2):161-8. https://doi.org/10.5271/sjweh.526

39. Podsakoff PM, MacKenzie SB, Lee J-Y, Podsakoff NP. Common method biases in behavioral research: A critical review of the literature and recommended remedies. J Appl Psychol. 2003;88(5):879-903. https://doi.org/10.1037/00219010.88.5.879

40. Ilmarinen JE. AGING WORKERS. Occup Environ Med. 2001 Aug 1;58(8):546-546. https://doi.org/10.1136/oem.58.8.546

41. Poscia A, Moscato U, La Milia DI, Milovanovic S, Stojanovic J, Borghini A, et al. Workplace health promotion for older workers: a systematic literature review. BMC Health Serv Res. [Internet]. 2016 Aug [cited 2017 May 10];16(S5). Available from: http://bmchealthservres.biomedcentral.com/ articles/10.1186/s12913-016-1518-z

42. van der Wel KA, Dahl E, Thielen K. Social inequalities in "sickness": does welfare state regime type make a difference? A multilevel analysis of men and women in 26 European countries. Int J Health Serv Plan Adm Eva. 2012;42(2):23555. https://doi.org/10.2190/HS.42.2.f

43. Ropponen A, Svedberg P, Koskenvuo M, Silventoinen K, Kaprio J. Physical work load and psychological stress of daily activities 
as predictors of disability pension due to musculoskeletal disorders. Scand J Public Health. 2014 Jun;42(4):370-6. https://doi.org/10.1177/1403494814525005

44. Lahelma E, Laaksonen M, Lallukka T, Martikainen P, Pietiläinen O, Saastamoinen P, et al. Working conditions as risk factors for disability retirement: a longitudinal register linkage study. BMC Public Health. 2012;12:309. https://doi. org/10.1186/1471-2458-12-309

45. Hultin H, Lindholm C, Malfert M, Möller J. Short-term sick leave and future risk of sickness absence and unemployment - the impact of health status. BMC Public Health. 2012 Oct 10;12:861. https://doi.org/10.1186/1471-2458-12-861

46. Borg K, Hensing G, Alexanderson K. Predictive factors for disability pension--an 11-year follow up of young persons on sick leave due to neck, shoulder, or back diagnoses. Scand J Public Health. 2001 Jun;29(2):104-12. https://doi. org/10.1080/14034940152393363

47. Robroek SJW, Schuring M, Croezen S, Stattin M, Burdorf A. Poor health, unhealthy behaviors, and unfavorable work characteristics influence pathways of exit from paid employment among older workers in Europe: a four year follow-up study. Scand J Work Environ Health. 2013 Mar 1;39(2):125-33. https://doi.org/10.5271/sjweh.3319
48. Reeuwijk KG, van Klaveren D, van Rijn RM, Burdorf A, Robroek SJW. The influence of poor health on competing exit routes from paid employment among older workers in 11 European countries. Scand J Work Environ Health. 2017 Jan 1;43(1):24-33. https://doi.org/10.5271/sjweh.3601

49. van den Berg T, Schuring M, Avendano M, Mackenbach J, Burdorf A. The impact of ill health on exit from paid employment in Europe among older workers. Occup Environ Med. 2010 Dec;67(12):845-52. https://doi.org/10.1136/ oem.2009.051730

50. Sundstrup E, Jakobsen MD, Mortensen OS, Andersen LL. Joint association of multimorbidity and work ability with risk of long-term sickness absence: a prospective cohort study with register follow-up. Scand J Work Environ Health. 2017 Mar 1;43(2):146-54. https://doi.org/10.5271/sjweh.3620

51. Knudsen AK, Øverland S, Aakvaag HF, Harvey SB, Hotopf M, Mykletun A. Common mental disorders and disability pension award: seven year follow-up of the HUSK study. J Psychosom Res. 2010 Jul;69(1):59-67. https://doi.org/10.1016/j. jpsychores.2010.03.007

Received for publication: 24 February 2017 